\title{
Epidemiological characteristics of and risk factors for breast cancer in the world
}

\author{
Zohre Momenimovahed ${ }^{1,2}$ \\ Hamid Salehiniya ${ }^{3,4}$ \\ 'Qom University of Medical \\ Sciences, Qom, Iran; ${ }^{2}$ Department \\ of Reproductive Health, Tehran \\ University of Medical Sciences, Tehran, \\ Iran; ${ }^{3}$ Social Determinants of Health \\ Research Center, Birjand University \\ of Medical Sciences, Birjand, Iran; \\ ${ }^{4}$ Department of Epidemiology and \\ Biostatistics, School of Public Health, \\ Tehran University of Medical Sciences, \\ Tehran, Iran
}

Correspondence: Hamid Salehiniya Social Determinants of Health Research Center, Birjand University of Medical Sciences, Birjand, Iran Tel +98935 7750428

Email alesaleh70@yahoo.com
This article was published in the following Dove Press journal: Breast Cancer - Targets and Therapy

\begin{abstract}
Aim: Breast cancer is the most common cancer among women and one of the most important causes of death among them. This review aimed to investigate the incidence and mortality rates of breast cancer and to identify the risk factors for breast cancer in the world.
\end{abstract}

Materials and methods: A search was performed in PubMed, Web of Science, and Scopus databases without any time restrictions. The search keywords included the following terms: breast cancer, risk factors, incidence, and mortality and a combination of these terms. Studies published in English that referred to various aspects of breast cancer including epidemiology and risk factors were included in the study. Overall, 142 articles published in English were included in the study. Results: Based on the published studies, the incidence rate of breast cancer varies greatly with race and ethnicity and is higher in developed countries. Results of this study show that mortality rate of breast cancer is higher in less developed regions. The findings of this study demonstrated that various risk factors including demographic, reproductive, hormonal, hereditary, breast related, and lifestyle contribute to the incidence of breast cancer.

Conclusion: The results of this study indicated that incidence and mortality rates of breast cancer is rising, so design and implementation of screening programs and the control of risk factors seem essential.

Keywords: breast cancer, risk factor, incidence, mortality, epidemiology

\section{Introduction}

Cancer is one of the main causes of mortality worldwide. ${ }^{1,2}$ In 2008,8 million deaths were recorded as a result of malignant diseases, and this figure is estimated to reach 11 million by $2030 .{ }^{3}$ Breast cancer is the most common cancer among women and one of the most important causes of death among them. ${ }^{4}$ Breast cancer is a multifactorial disease $^{5}$ and various factors contribute to its occurrence. Although the disease occurs all over the world, its incidence, mortality, and survival rates vary considerably among different parts of the world, which could be due to many factors such as population structure, lifestyle, genetic factors, and environment. ${ }^{6}$ Changes in risk factors have led to an increase in the prevalence of breast cancer, which is increasing every day. ${ }^{7}$ Although screening people can reduce the burden of breast cancer, side effects, overdiagnosis, and increased costs are the disadvantages of this method. Classification of women based on risk factors for breast cancer can be effective in improving risk-free methods and designing targeted breast cancer screening programs. ${ }^{8}$

Review articles are one of the main resources for program design and policy making and can provide a clear view of the various aspects of a phenomenon for researchers. ${ }^{9}$ 
This review aimed to investigate the prevalence and mortality rate of breast cancer and also to identify the risk factors for breast cancer in the world by combining and summarizing the results of various population-based studies conducted in the world.

\section{Materials and methods \\ Search method}

Both authors performed searches in PubMed, Web of Science, and Scopus databases without any time restrictions. The search keywords included the following terms: breast cancer, risk factors, incidence, and mortality and a combination of these terms. A list of related articles was also searched, and studies published in English that referred to various aspects of breast cancer including epidemiology and risk factors were included in the study. Qualitative studies, studies related to therapeutic and diagnostic aspects, and studies with insufficient focus on the goals of this study were excluded from the present study. Studies were selected based on the review of the article title, abstract, and full text of the articles. In the initial search, 765 articles were obtained from three databases and 54 articles were obtained using manual search. After removing duplicates, the titles and abstracts of 625 articles were reviewed using EndNote software. After the initial screening, 207 articles were included in the study, of which 59 articles were excluded for scientific reasons (editorial: 3, insufficient data: 16, duplicate: 16, qualitative studies: 7 , case reports: 4 , full text not available: 13). Finally, 148 articles published in English were included in the study.

\section{Results}

\section{Types of breast cancer}

Based on various factors such as etiology, clinical presentation, molecular characteristics, and response to treatment, breast cancer was divided into different groups. ${ }^{10}$ The estrogen receptor (ER), the progesterone receptor (PR), and the HER2 are the most commonly used classification of invasive breast cancer, which is used to provide therapeutic approaches and to predict clinical outcomes. ${ }^{11}$ The incidence rate of different hormone receptor-positive breast cancer varies in different regions. Milne et $\mathrm{al}^{12}$ found that ER-negative breast cancer was correlated with breast cancer risk in BRCA1 mutation carriers. In a study among women 50 years of age and older, relative to non-Hispanic whites, women of certain ethnic group (African Americans, Native Americans, Filipinos, Chinese, Koreans, Vietnamese, Indi-
ans/Pakistanis, Mexicans, South/Central Americans, and Puerto Ricans living in the United States) 1.4- to 3.1-fold more likely to have estrogen receptor-negative/progesterone receptor-negative breast cancer. ${ }^{13}$ Yip et al in a study in Malaysia showed that ethnicity and grade were significantly associated with ER positivity rates. They stated that between 1994 and 2008, every 5 years, the proportion of ER+ breast cancers increased by $2 \% .{ }^{14}$ The results of a study in Southeast Asia showed that Malay and Indian women were more likely to have unfavorable tumor characteristics such as hormonal negative, poorly differentiated tumors, high-grade tumors, and thus poorer survival after breast cancer. ${ }^{15}$ In a study by Parise et al, ${ }^{16}$ Asian Pacific Islanders had an increased risk of having the ER-/PR-/HER2+ subtype. Another study that was conducted by Yamashita et al ${ }^{17}$ showed that ER-positive tumors significantly increased among Japanese women.

\section{Incidence}

Breast cancer is the second most common cancer in the world and the most common cancer among women. ${ }^{4}$ Lifetime risk of developing breast cancer in every woman in the United States is $12.4 \%$ or one in eight women. ${ }^{18}$ In 2012 , 1.67 million new cases of breast cancer were identified worldwide, accounting for $25 \%$ of all cancers. ${ }^{4}$ Although cancer exists anywhere in the world, its incidence rate is higher in developed countries, and the incidence rate of breast cancer varies greatly with race and ethnicity. ${ }^{19}$ The incidence rate of breast cancer varies among different parts of the world, ${ }^{20}$ varying from 27 per 100,000 in Middle Africa and East Asia to 92 per 100,000 in Northern America. ${ }^{4}$ The incidence rate of breast cancer is estimated to reach 3.2 million by $2050 .{ }^{6}$ With increasing population age in developed countries, the incidence rate of breast cancer among older people is increasing. ${ }^{6}$ In 2017, approximately 252,710 new cases of invasive breast cancer and 6,341 cases of breast cancer in situ were diagnosed in the United States. ${ }^{18}$ Nearly $24 \%$ of all breast cancer cases occur in the Asia-Pacific region, with the highest rates seen in China, Japan, and Indonesia. ${ }^{21,22}$ In addition to Japan, the prevalence of breast cancer is increasing among Asian and American women, with Korea accounting for the highest prevalence of breast cancer in 1988-2006 and Southeast Asia in 1988-2013. ${ }^{23}$ It was estimated that 277,054 new cases of breast cancer were diagnosed in East Asia in 2012. This figure was 107,545 in Southeast Asia and 223,899 in south-central Asia. ${ }^{24}$ Due to better access to screening and 
therapeutic programs, the survival rate of breast cancer is increasing, and the 5 -year survival rate was $89 \%$ between 2005 and $2011 .^{25}$ The 1-year survival rate of breast cancer in European countries varies from $94.1 \%$ in Scotland to $97.1 \%$ in Italy. ${ }^{26}$ Because of the delay in seeking diagnosis of and treatment for breast cancer among African women, survival rate is low among them. ${ }^{27}$ The incidence (agestandardized rate per 100,000) of breast cancer in different regions of the world is as follows: more developed regions: 74.1, less developed regions: 31.3, Western Europe: 96.0, Northern America: 91.6, Northern Europe: 89.4, Australia/ New Zealand: 85.8, South-Central Asia: 28.2, and Eastern Asia: $27.0 .{ }^{166}$

\section{Mortality}

Breast cancer is the fifth leading cause of cancer death in 2012 worldwide, with a record of 324,000 deaths in 2012 , and it was the most common cause of death in less developed countries. Also, with 197,000 deaths accounting for $15.4 \%$ of all deaths, breast cancer was the second cause of death in developed countries after lung cancer. ${ }^{4}$ The mortality rate of breast cancer is estimated to increase by 2020 in many parts of Europe. ${ }^{28}$ Although the prevalence of breast cancer is higher in developed countries, higher mortality rates are observed in less developed regions. ${ }^{29}$ Furthermore, $89 \%$ of deaths from breast cancer in the United States in 2017 occurred in women aged 50 years or older. ${ }^{18}$ Due to improved therapeutic and diagnostic methods and the promotion of breast cancer management in the high-income countries, a significant reduction in mortality rate of breast cancer is seen in these countries. ${ }^{30}$ The age-standardized mortality rate (ASMR) of breast cancer in the world is 12.9 (31) and Africa has the highest ASMR around the world. ${ }^{32}$ The mortality rate varies from six cases per 100,000 people in East Asia to 20 cases per 100,000 people in Western Africa. ${ }^{4}$ The mortality-to-incidence rate ratio in North America is 0.16 , which indicates a higher survival rate, and in Asia it is between 0.23 and 0.48. ${ }^{31}$ Most Asian countries are low- to middle-income countries, and therefore, breast cancer is one of the main causes of mortality in these countries. ${ }^{33}$ The mortality (age-standardized rate per 100,000) of breast cancer in different regions of the world is as follows: More developed regions: 14.9, less developed regions: 11.5, Western Europe: 16.2, Northern America: 14.8, Northern Europe: 16.4, Australia/ New Zealand: 14.5, South-Central Asia: 13.5, and Eastern Asia: 6.1.166

\section{Risk factors}

Table 1 shows factor related to breast cancer.

\section{Demographic factors Gender}

Breast cancer is often a disease that is unique to women and is a rare malignancy in men, accounting for less than $1 \%$ of all cases of cancer. ${ }^{34}$ Breast cancer occurs more often in older adult males who have had hormonal imbalance, exposure to radiation, and family history of breast cancer, and the most common risk factor for this disease among men is mutation of $B R C A 2$ gene. $^{34,35}$

\section{Age}

After gender, age is the most important known risk factor for breast cancer. ${ }^{36}$ The incidence rate of breast cancer increases significantly with age and reaches its peak in the age of menopause and then gradually decreases or remains constant. ${ }^{31}$ In a case-control study, the age more than 50 years was associated with the incidence rate of breast cancer. ${ }^{37}$ However, breast tumors in younger women appear in larger size, advanced stages, positive lymph nodes, and weaker survival. ${ }^{38}$

\section{Blood group}

The results of a review study showed that women with blood group A and Rhesus positive have a higher risk of developing breast cancer, while women with blood group $\mathrm{AB}$ and Rhesus negative have a lower risk of developing breast cancer. ${ }^{39}$ Although these results were confirmed by a study in $2015,{ }^{40}$ many researchers found no relationship between the blood group and breast cancer. ${ }^{41,42}$

\section{Reproductive factors}

The correlation between reproductive factors and breast cancer is related to the effect of ovarian hormones that begin at the puberty age and continues during the monthly cycles, and these hormones are also affected by the number of pregnancies and ultimately decrease in menopause. ${ }^{36}$

\section{Age of menarche}

The findings of a case-control study indicated that younger age during menarche increases the risk of breast cancer by two times (OR, 2.83; 95\% CI, 1.02-7.86). ${ }^{36}$ This result has been confirmed by many other studies. ${ }^{31,43-45}$ The result of a large population cohort study of 11,889 women in China 
Table I Risk factors related to the breast cancer in the world

\begin{tabular}{|c|c|c|c|c|}
\hline \multicolumn{2}{|l|}{ Risk factors } & \multirow[t]{2}{*}{ Protective } & \multirow{2}{*}{\begin{tabular}{|l|} 
Predisposing \\
$\checkmark$
\end{tabular}} & \multirow[t]{2}{*}{ Controversial } \\
\hline Demographic & Female gender & & & \\
\hline & Age & & $\checkmark$ & \\
\hline & Blood group & & & $\checkmark$ \\
\hline \multirow[t]{6}{*}{ Reproductive } & Age of menarche & & & $\checkmark$ \\
\hline & Late age of menopause & & $\checkmark$ & \\
\hline & Full-term pregnancy & $\checkmark$ & & \\
\hline & Abortion & & & $\checkmark$ \\
\hline & Ovulatory menstrual cycle & $\checkmark$ & & \\
\hline & Pregnancy characteristics & $\checkmark$ & $\checkmark$ & \\
\hline \multirow[t]{3}{*}{ Hormonal } & Hormonal contraceptive methods & & $\checkmark$ & \\
\hline & Ovulation-stimulating drugs & & & $\checkmark$ \\
\hline & Postmenopausal hormone therapy & & $\checkmark$ & \\
\hline \multirow[t]{2}{*}{ Hereditary } & Genetic factors & & $\checkmark$ & \\
\hline & Positive family history of breast cancer & & $\checkmark$ & \\
\hline \multirow[t]{3}{*}{ Breast related } & Lesser lactation duration & $\checkmark$ & & \\
\hline & More breast density & & & $\checkmark$ \\
\hline & Benign breast disorders & & $\checkmark$ & \\
\hline \multirow[t]{8}{*}{ Lifestyle } & Obesity and overweight & & $\checkmark$ & \\
\hline & Alcohol consumption & & $\checkmark$ & \\
\hline & Smoking & & $\checkmark$ & \\
\hline & Coffee & & & $\checkmark$ \\
\hline & Diet & & $\checkmark$ & \\
\hline & More physical activity & $\checkmark$ & & \\
\hline & Vitamin D & $\checkmark$ & & \\
\hline & Duration of sleep & & & $\checkmark$ \\
\hline \multirow[t]{5}{*}{ Others } & Air pollution & & $\checkmark$ & \\
\hline & Night work & & $\checkmark$ & \\
\hline & Socioeconomic status & & $\checkmark$ & \\
\hline & Diabetes & & $\checkmark$ & \\
\hline & Radiation & & $\checkmark$ & \\
\hline
\end{tabular}

showed that younger age during menarche is associated with an increased risk of breast cancer (95\% CI, 1.1-3.4). ${ }^{46}$ However, in other studies, younger age during menarche was not associated with an increased risk of breast cancer. ${ }^{47,48} \mathrm{~A}$ study in Italy showed no relationship between breast cancer and duration of menstruation cycles. ${ }^{49}$

\section{Age of menopause}

The age of menopause over 50 years is associated with an increased risk of breast cancer. ${ }^{31,44,50}$ The results of a casecontrol study also confirmed the association between older age in menopause and the incidence of breast cancer (OR, 2.43 ; $95 \%$ CI, $1.2-4.9) .{ }^{36}$

\section{Full-term pregnancy}

Among parous women, the risk of breast cancer decreases with increasing parity. ${ }^{31,45,51}$ In a case-control study, older age during the first childbirth was the most important risk factor for breast cancer, with relative risk of more than six times (OR, 6.34; 95\% CI, 2.04-27). ${ }^{36}$ A study indicated that every childbirth reduces the risk of PR+ and ER+ cancers by up to $10 \%$ (RR per birth, $0.89 ; 95 \%$ CI, 0.84-0.94), and women who were older at their first childbirth had a $27 \%$ increased risk of developing breast cancer ( $R R, 1.27 ; 95 \%$ CI, 1.07-1.50). ${ }^{52}$ The results of the studies showed that fullterm pregnancy is considered as a protective factor. ${ }^{50,51}$ The results of a study showed that breast cancer is more likely to occur in nulliparous women than women who have more than three children (OR, 1.98; 95\% CI, 1.12-3.49). ${ }^{53}$ However, in some studies, multiparity was associated with a reduced risk of developing breast cancer, ${ }^{44,47}$ and based on the results of a case-control study, having more than five full-term pregnancies is associated with an increased risk of breast cancer. ${ }^{37}$ In a study of African-American women, high parities were associated with an increased risk of developing breast cancer among people younger than 45 years (incidence rate ratio [IRR] for 
four or more births, 2.4; 95\% CI, 1.1-5.1) and a decreased risk among people older than 45 years (IRR, 0.5; 95\% CI, $0.3-0.9) .{ }^{54}$ In a prospective cohort study, nulliparity was associated with large tumors (>20 mm; RR, 1.89; 95\% CI, 0.91-3.91), high Ki67 levels (RR, 1.95; 95\% CI, 0.93-4.10), high cyclin D1 levels (RR, 2.15; 95\% CI, 0.88-5.27), grade III (RR, 2.93; 95\% CI, 1.29-6.64), and HER2-positive tumors (RR, 3.24; 95\% CI, 1.02-10.25). ${ }^{55}$

In addition to full-term pregnancy, early maternal age reduces the risk of developing breast cancer by up to $23 \%$. ${ }^{44}$ There is a positive correlation between the age of more than 26 years during the first childbirth and lobular disease (OR, 1.35; 95\% CI, 1.03-1.78). ${ }^{56}$ Older age at first full-term pregnancy is associated with an increased risk of developing breast cancer. ${ }^{31,37,44,47}$ In a case-control study, first full-term pregnancy in women aged 20 years or older is associated with $40 \%-50 \%$ increased risk of breast cancer. ${ }^{45}$ Older age at the last childbirth is also associated with an increased risk of developing breast cancer (OR, 2.15; 95\% CI, 1.52-3.08), although no significant relationship was found between the breast cancer and the time of last childbirth in the another study. ${ }^{54}$

\section{Abortion}

The results of a study showed that higher incidence rate of abortion was associated with an increased risk of developing breast cancer (OR, 6.26; 95\% CI, 4.16-9.41). ${ }^{43}$ However, this finding was not confirmed in another study. The reanalysis of findings from 53 epidemiologic studies showed that selfinduced or natural abortion does not increase the risk of developing breast cancer. ${ }^{57}$

\section{Ovulatory menstrual cycle}

The ovulatory menstrual cycle may have a protecting role against breast cancer (OR, 0.44; 95\% CI, 0.23-0.81). ${ }^{53}$

\section{Pregnancy characteristics}

Pregnancy, especially the first pregnancy, plays an important role in the risk of developing breast cancer. The results of studies showed that the risk of breast cancer is almost doubled in women who give birth to their first child before the 33 weeks of gestation (OR, 2.1; 95\% CI, 1.2-3.9).$^{58,59}$ In a study, the risk of developing breast cancer increased in multiple births (OR, 1.8; 95\% CI, 1.1-3.0). ${ }^{58}$ Moreover, the results of this study showed a relationship between placental abruption in the first pregnancy and an increased risk of developing breast cancer (OR, 1.8; 95\% CI, 1.1-3.0). ${ }^{58}$ The results of various studies indicated the protective role of preeclampsia in breast cancer, ${ }^{58,60-62}$ which can be due to decreased levels of estrogen hormone and insulin-like growth factor 1 (IGF1) and increased levels of IGF-1-binding protein, hCG, and AFP. ${ }^{58}$ The result of a case-control study showed an inverse relationship between nausea and vomiting during pregnancy and the risk of developing breast cancer. ${ }^{62}$

\section{Hormonal factors}

\section{Contraceptive methods}

The role of contraceptive pills in the incident of breast cancer has been addressed in various studies. ${ }^{63-65}$ Based on the results of a case-control study, the use of oral contraceptive pill is associated with an increased risk of developing breast cancer (OR, 9.50; 95\% CI, 3.38-26.7). ${ }^{43}$ This result was confirmed in other studies. ${ }^{44,49,50}$ Meanwhile, according to the findings of a study by McDonald and coworkers, ${ }^{65}$ which was conducted on 35- to 64-year-old women, current (RR, 1; 95\% CI, 0.8-1.3) or previous use (RR, $0.9 ; 95 \%$ CI, $0.8-1$ ) of contraceptive pills was not associated with an increased risk of developing breast cancer. Williams et $\mathrm{al}^{56}$ showed a relationship between the current use of contraceptives and breast lobular tumors (OR, 1.86; 95\% CI, 1.08-3.20). Researchers, regarding the association of medroxyprogesterone acetate with breast cancer, have stated that this correlation may be due to the diagnosis of mammary tumors or the growth of existing mammary tumors. ${ }^{66}$ An increased risk of developing breast cancer diminishes 5-10 years after the discontinuation of hormonal contraceptives. ${ }^{67}$

\section{Ovulation-stimulating drugs}

The result of a case-control study showed that using ovulation-stimulating medications for more than 6 months increases the risk of developing breast cancer. ${ }^{68}$ However, this finding was not confirmed in other studies. ${ }^{69,70}$

\section{Postmenopausal hormone therapy}

A reanalysis of 51 epidemiological studies showed that risk of developing breast cancer increases with the hormone replacement therapy (HRT) use (RR, 1.023; 95\% CI, 1.011-1.036), and this risk decreases following the discontinuation of HRT use and diminishes after 5 years. ${ }^{71}$ Results of a study that examined 1 million women found that the current use of HRT is associated with the increased mortality rate and risk of developing breast cancer (adjusted RR, 1.66; 95\% CI, $1.58-1.75)$, and this risk is higher in those who use estrogen-progesterone combination methods than in those who use other HRT methods (RR, 2.00; 95\% CI, 1.88-2.12). ${ }^{72}$ These results are consistent with the results of a study that 
stated that adding progesterone to HRT treatment significantly increases the risk of developing breast cancer (OR, $1.24 ; 95 \% \mathrm{CI}, 1.07-1.45) .{ }^{73}$ In a cohort study, the researchers emphasized that the selection of progesterone in HRT should be based on the risk of developing breast cancer. They reported that this risk is lower in estrogen-progesterone or estrogen-dydrogesterone methods than other methods. ${ }^{74}$ The result of a case-control study showed that the use of HRT in postmenopausal women and in carriers of BRCA1 mutations does not increase the risk of developing breast cancer. ${ }^{72}$

\section{Hereditary factors}

\section{Genetic factors}

Although several genetic factors contribute to the incidence of breast cancer, approximately $40 \%$ of hereditary breast cancer cases occur due to mutations in the BRCA1 and BRCA2 genes inherited through the dominant autosomal method. ${ }^{75}$ The results of a study show that $55 \%-65 \%$ of carriers of $B R C A 1$ mutation and $45 \%$ of carriers of BRCA2 mutation develop breast cancer by the age of 70 years. ${ }^{76}$ Based on a prospective cohort study, the risk of cumulative breast cancer by the age 80 years was $72 \%$ in the carriers of BRCA1 mutation $(95 \% \mathrm{CI}, 65 \%-79 \%)$, and this amount was $69 \%$ in the carriers of $B R C A 2$ mutation (95\% CI, $61 \%-77 \%) .{ }^{77}$ Changes in human interferon $\alpha-2 b$ may be involved in the onset and progression of breast cancer in addition to other risk factors. ${ }^{78}$ In a case-control study, matrix metalloproteinase (MMP-2 c-735-T) polymorphisms were associated with an increased risk of developing breast cancer. Furthermore, MMP-2c allele may also increase the risk of developing breast cancer at a younger age by 1.64 -fold (OR, 1.64; 95\% CI, 1.01-2.7). ${ }^{79}$

\section{Family history of breast cancer}

Family history of breast cancer is one of the major risk factors, which has been mentioned in various studies. ${ }^{36,37,43,80-82}$ Researchers reported that women with a family history of breast cancer (two or more cases in women younger than 50 years or three or more cases at any age) who are negative in terms of $B R C A$ mutations are approximately 11 times more likely to develop breast cancer. ${ }^{83}$ The history of early-onset breast cancer in immediate relatives is a risk factor for the occurrence of breast cancer in BRCA1 and BRCA2 carriers. ${ }^{84}$ Based on the result of a case-control study, the history of breast cancer is associated with a twofold increase in the risk of developing contralateral breast cancer (RR, 2.1; 95\% CI, 1.4-3.0) ${ }^{84}$ In a hospital-based cohort of 5,359 women, no relationship was found between the family history of breast cancer and the severity and mortality associated with the breast cancer (adjusted proportional OR, 1.00; 95\% CI, 0.85-1.17). Accordingly, researchers stated that the clinical management of breast cancer among women with or without family history of breast cancer and knowledge of underlying mutations should not be different. ${ }^{85}$ Having a family history of breast cancer may candidate individual for chemoprevention with tamoxifen or intensified breast screening with a magnetic resonance imaging. ${ }^{83}$

\section{Breast-related factors}

\section{Lactation}

Breast feeding is a protective factor against breast cancer, and many researchers have pointed to the role of lactation in breast cancer prevention. ${ }^{31,86}$ Based on the results of various studies, the length of lactation is associated with breast cancer. ${ }^{43,44,50,87}$ The protective effect of lactation increases with increasing duration of lactation. ${ }^{44}$ The result of a casecontrol study showed that the combination of two protective factors (two or more childbirth and lactation for more than 13 months) could reduce the risk of developing breast cancer by up to $50 \%{ }^{88}$ Furthermore, breastfeeding may be associated with improvements in prognosis and a decreased rate of recurrence (HR, 0.70; 95\% CI, 0.53-0.93) and an increased rate of survival among breast cancer patients, although this effect is different in different ER states. ${ }^{89}$ The protective effect of breast feeding on breast cancer risk has not been proven in other studies. ${ }^{90,91}$

\section{Breast density}

Breast density, which means the amount of total dense tissue in the breast, ${ }^{87}$ has been described in numerous studies as an independent risk factor for breast cancer. ${ }^{80,87}$ In an observational cohort study, there was no correlation between breast density and breast cancer in women with atypical hyperplasia. ${ }^{92}$ Based on the results of a case-control study, breast density increased after initiating estrogen and progesterone administration, showing an increase of $3.4 \%$ in the risk of developing breast cancer with every $1 \%$ increase in the breast density. ${ }^{93}$ Based on the results of a cohort study, breast density was associated with an increase in the risk of ER-positive (HR, 2.13; 95\% CI, 1.89-2.40) and ER-negative invasive breast cancer (HR, 1.68; 95\% CI, 1.34-2.11), and the rate of this increase decreased with the age. ${ }^{94}$ Although the results of a prediction protocol showed a fivefold increase in the risk of developing breast cancer in high breast density patients, ${ }^{95}$ the results of a cohort study showed no relationship between breast cancer and breast density. ${ }^{81}$ 


\section{Benign breast disorders}

Cancer is a multifactorial disease, and benign breast diseases are one of the most important risk factors for breast cancer. ${ }^{5,49,96} \mathrm{The}$ results of a cohort study indicated that benign breast diseases are associated with an increased risk of ER-positive and ERnegative invasive breast cancer, and the rate of this increase is different in different age. ${ }^{94}$ However, in another study, atypical hyperplasia may only be seen in $5 \%$ of women with fibrocystic mastosis. ${ }^{97}$ The results of a case-control study indicated that HRT and breast hyperplasia are associated with an increased risk of developing breast cancer in patients with benign breast disease (OR, 5.56; 95\% CI, 2.05-15.06). The risk of breast cancer decreases in postmenopausal women with benign breast disease.$^{98}$ The researchers, after conducting another study, concluded that the association between benign breast disorders and breast cancer depends on the histological classification of the disease and family history of breast cancer. ${ }^{99}$

\section{Lifestyle factors Obesity and overweight}

The correlation between obesity and breast cancer has been considered in several studies. . $^{31,80,94,100,101}$ Obesity is correlated with breast cancer due to higher rates of conversion of androgenic precursors to estrogen through peripheral aromatization in adipose tissue. On the other hand, high levels of insulin and insulin-like factors in response to obesity can stimulate the growth of cancer cells. ${ }^{102}$ According to a prospective observational study, among 74,177 women, $17 \%$ of ER+/PR+ postmenopausal breast cancer and $14 \%$ of postmenopausal breast cancer attributed to the weight gain of more than 5 $\mathrm{kg}$ from the age of 18 years. ${ }^{103}$ Results of a study showed that prepregnancy obesity is an independent risk factor for long-term malignancies, such as ovarian and breast cancer (adjusted HR, 1.4; 95\% CI, 1.1-1.9). ${ }^{104}$ Body mass index (BMI) also plays a role in survival of patients and is an independent predictor of overall survival in patients with breast cancer. ${ }^{105}$ Results of a study showed that postmenopausal women who were obese $\left(\mathrm{BMI} \geq 30 \mathrm{~kg} / \mathrm{m}^{2}\right)$ at the time of breast cancer diagnosis had a lower disease-free survival (HR, 1.43; 95\% CI, 1.11-1.86) and overall survival (HR, 1.56; 95\% CI, 1.14-2.14) compared to nonobese women. ${ }^{106}$ Researchers of a prospective cohort study reported that obesity mainly affects the elderly. ${ }^{102} \mathrm{~A}$ cohort study also showed a positive correlation between breast cancer and the height. ${ }^{107}$

\section{Alcohol consumption}

In various studies, the role of alcohol carcinogens and its correlation with breast cancer has been addressed. ${ }^{100,108}$
Results of a European Prospective Investigation into Cancer and Nutrition (EPIC) showed a relationship between alcohol consumption and the hormone receptor-positive and hormone receptor-negative breast tumors. The results of this study showed that time of alcohol consumption can affect the risk of developing breast cancer, and the risk of developing breast cancer is higher among those who consume alcohol before the first full-term pregnancy. ${ }^{109}$ In a case-control study, after the old age in the first childbirth, alcohol consumption, with a 4.2-fold increase, was one of the main risk factors for breast cancer. ${ }^{36}$ In a population-based case-control study, there was a correlation between alcohol consumption and ER+ invasive lobular carcinoma (OR, 1.25; 95\% CI, 0.99-1.58) and ER+ invasive ductal carcinoma. ${ }^{110}$ These results were also confirmed in another study. ${ }^{11}$

\section{Smoking}

Active smoking (HR, 1.16; 95\% CI, 1.00-1.34), especially in postmenopausal women, ${ }^{112}$ and prenatal smoking (HR, 1.18; $95 \%$ CI, $1.10-1.27$ for every increase of 20 pack-years) ${ }^{113}$ are associated with an increased risk of developing breast cancer. The result of a study showed that spouses' exposure to passive smoking is a risk factor for developing breast cancer, and in particular, this contributes to the increased risk of ER +/PR+ double-positive breast cancer (adjusted OR, 1.46; 95\% CI, $1.05-2.03 ; P=0.027) .{ }^{114}$ According to the results of a study, there is a consistent dose-response relationship between the number of years of smoking before the first childbirth (HR, $1.60 ; 95 \% \mathrm{CI}, 1.42-1.80$ ) and the risk of developing breast cancer in short-term and long-term smokers, as well as in those who smoke 10 or more cigarettes per day. ${ }^{115}$

\section{Coffee}

Overall, the data on coffee consumption and breast cancer risk are controversial. Although different studies did not support the role of coffee in breast cancer risk, ${ }^{116,117}$ a case-control study revealed that increase in daily coffee consumption was correlated with significant decrease in ER-negative breast cancer among postmenopausal women. ${ }^{118}$ In a study by JK et al, ${ }^{119}$ authors found negative association between coffee intake and ER+/PR- breast tumors. Ganmaa et al conducted a cohort study and have not found the relationship between coffee and risk of developing breast cancer. However, they stated that there was a weak inverse association between coffee and postmenopausal breast cancer. ${ }^{120}$ On the contrary, Yaghjyan et al ${ }^{121}$ stated that drinking coffee is associated with an increased risk of developing breast cancer among people who have used hormone in the past. 


\section{Diet}

The relationship between diet and nutrition and cancer has been the focus of many researchers and has been addressed in various studies. In a case-control study, there was a relationship between nonvegetarian diet and breast cancer. ${ }^{36}$ The result of a case-control study showed that diet containing low polyunsaturated and saturated fatty acids in breast cancer is more important than overall fat intake. ${ }^{122}$ The results of another study showed that the risk of developing breast cancer increases with the increase in total consumption of meat (HR, 1.20; 95\% CI, 0.86-1.68) and nonprocessed meat (HR, 1.20; 95\% CI, 0.86-1.68). ${ }^{123}$ The results of a European prospective study on cancer and nutrition showed a significant association between saturated fat consumption and the risk of developing breast cancer (HR, 1.13; 95\% CI, 1.00-1.27; $P$ for trend, 0.038). ${ }^{124}$ However, Harris et $\mathrm{al}^{125}$ found that diet during adolescence could increase the incidence rate of breast cancer at premenopausal age. The result of a study showed that the distributions of $\mathrm{Fe}, \mathrm{Cu}$, and $\mathrm{Zn}$ concentrations were higher in malignant tissues than in benign tissues. The researchers pointed out that this may be the cause or outcome of breast cancer. ${ }^{126}$

\section{Physical activity}

The results of a prospective cohort study of 74,171 women aged 50-79 years showed that increased physical activity is associated with a reduction in the risk of developing breast cancer in postmenopausal women. In this study, more physical activity was associated with more benefits (RR, 0.86; 95\% CI, 0.78-0.95). ${ }^{127}$ Researchers in an observational study stated that physical activity after the diagnosis of breast cancer may reduce the risk of death as a result of the disease. They stated that the greatest benefit of exercise was seen among people who had 3-5 hours walking per week at an average speed. ${ }^{128}$ Reducing mortality and morbidity of breast cancer in people who exercise have also been confirmed in other studies. ${ }^{31,129,130}$

\section{Vitamin D}

According to the results of a study, there is an inverse relationship between the serum $25 \mathrm{OH}$ vitamin $\mathrm{D}$ and breast tumor size in patients with breast cancer. Moreover, this study showed an improvement in the outcomes of breast cancer with appropriate status of vitamin D. ${ }^{131}$ The result of a case-control study showed that women with vitamin D deficiency have $27 \%$ increased risk of developing breast cancer compared to those with normal serum $25 \mathrm{OH}$ vitamin $\mathrm{D}$ levels. ${ }^{132}$ Researchers have confirmed this conclusion and stated that fourth quartile of $25 \mathrm{OH}$ vitamin $\mathrm{D}$ level has three times the risk of developing breast cancer compared to the first quartile. ${ }^{132}$ In a cohort study, serum levels above $25 \mathrm{OH}$ vitamin D and regular use of vitamin D supplement were associated with a reduction in the incidence rate of breast cancer after menopause over a 5-year follow-up period. ${ }^{133}$ Finally, Shekarriz-Foumani and Khodaie, ${ }^{134}$ in a systematic review, found that vitamin $\mathrm{D}$ deficiency is common among mammary neoplasms and the risk of developing breast cancer increases by decreasing the level of vitamin D.

\section{Duration of sleep}

There is a relationship between sleep duration and breast cancer. Compared to women with normal sleep duration, women with longer sleep duration may be at an increased risk of developing breast cancer. However, in this study, this association was not seen in women with shorter sleep time. ${ }^{135}$ Xiao et al $^{136}$ stated that short sleep duration is associated with an increased risk of hormone receptor-positive breast cancer. The findings of a retrospective cohort study showed that insomnia is associated with an increased risk of developing breast cancer (adjusted HR, 1.43; 95\% CI, 1.10-1.84). ${ }^{137}$ Another study showed that different aspects of sleep, such as sleep duration and quality, are associated with an increased risk of aggressive breast tumors, and the severity of this association depends on the race of people. ${ }^{138}$ The duration of sleep does not affect the prognosis in people who have been saved from cancer. ${ }^{139}$ The result of a prospective cohort study did not show any relationship between sleep and breast cancer. ${ }^{140}$

\section{Other risk factors \\ Air pollution}

The result of a study showed a relationship between air pollution and the incidence rate of breast cancer in postmenopausal European women. ${ }^{141}$ Wei et al ${ }^{142}$ stated that breast cancer is more common in urban areas and areas with high levels of pollution. The result of 15 cohort studies from nine European countries also reported an association between air pollution and the incidence rate of postmenopausal breast cancer in European women. ${ }^{143}$

\section{Night work}

The result of a study showed that overnight working is associated with an increased moderate risk of developing breast cancer, and this connection is stronger in women who have been working for more than 20 years. ${ }^{144}$ Exposure to artificial light at night sharply reduces the level of melatonin and is 
thought to increase the risk of developing breast cancer. ${ }^{145}$ This reduction in melatonin production leads to an increase in the levels of reproductive hormones such as estrogen, which is effective in the development of hormone-sensitive breast tumors. ${ }^{146}$ The result of a meta-analysis showed that shift work increases the risk of breast cancer by up to $48 \%{ }^{147}$

\section{Socioeconomic status}

One of the issues that have been discussed in more detail in recent studies is the role of socioeconomic status in the incidence rate of breast cancer. In various studies, there was a relationship between high socioeconomic status and breast cancer. ${ }^{36,148}$ Breast cancer is higher in women with higher socioeconomic status, which can be due to the direct effects of important risk factors such as paralysis, and older age at the first childbirth and during menopause. ${ }^{149}$ In addition, sedentary lifestyle and a high-fat diet in this social class can directly and indirectly affect the menstrual cycle of women. ${ }^{36}$ On the one hand, access to care and prevention, diagnosis, and prevention of breast cancer is also higher in these women. ${ }^{150}$ The educational leve ${ }^{49}$ and employment status (OR, 0.32; CI, $0.19-0.56)^{53}$ are among the most important socioeconomic variables that affect the incidence rate of breast cancer. Researchers believe that employed women generally have higher income and are more likely to use health insurance. In addition, the economic situation can contribute to the person's willingness to spend money on medical care. ${ }^{53}$ Due to differences in lifestyle, diet, and environmental factors, living in urban areas is associated with an increase in the risk of developing breast cancer. ${ }^{53}$ In the low social class, lower levels of vitamin $\mathrm{C}$, retinol and beta carotene, and high level of fat intake can be found, which is associated with changes in levels of estrogen and prolactin hormones in the incidence of breast cancer. ${ }^{151}$ Socioeconomic status can significantly alter the outcome of patient in cases of relapse and death. In addition, researcher considers the socioeconomic status as an important indicator of disease-free survival and overall survival. ${ }^{151}$ The socioeconomic status is associated with the clinical course ${ }^{152}$ and survival rate $(7 \%$ absolute difference in overall survival, $P<.001 ; 4 \%$ cancer-specific survival, $P<0.001){ }^{153}$

\section{Diabetes}

Diabetes can affect the incidence of breast cancer by interfering with biological mechanisms or through its effects on screening and treatment. ${ }^{154}$ The results of the studies show that diabetes is associated with the risk of breast cancer progress among postmenopausal women and those with higher BMI (OR, 4.928; 95\% CI, 2.1-11.3). ${ }^{155}$ Findings of a meta-analysis revealed that women with diabetes (especially those with type II diabetes) are at $20 \%$ increased risk of developing breast cancer. ${ }^{156}$ Researchers suggest that in postmenopausal women and in people with BMI of greater than $26 \mathrm{~kg} / \mathrm{m}^{2}$, the levels of blood glucose, insulin, and IGF-1 patterns are associated with an increased risk of developing breast cancer. ${ }^{157}$ The use of metformin can improve the overall survival rate in people with breast cancer and type II diabetes. ${ }^{158}$ According to EPIC, in addition to endocrine factors, in women with higher levels of IGF-1 and insulin-like growth factor binding protein-3 (IGFBP-3) than normal, the risk of developing breast cancer is significantly increased, and this association is stronger in those whose tumors are detected after the age of 50 years (highest vs lowest quintile OR, 1.38 [95\% CI, 1.02-1.86], $P=0.01$, and 1.44 [95\% CI, 1.04-1.98], $P=0.01$, respectively). ${ }^{159}$ The control of $\mathrm{HbA1C}$ below $7 \%$ can improve the outcome of women with breast cancer. ${ }^{160}$

\section{Radiation}

A large population-based case-control study found that the risk of developing breast cancer in women, who are faced with radiation due to the history of previous cancer treatment (OR, 3.55; 95\% CI, 1.47-8.54), screening or tuberculosis (OR, 2.49; 95\% CI, 1.82-3.40), or pneumonia monitoring (OR, 2.19; 95\% CI, 1.38-3.47), is two to three times higher. ${ }^{161}$ On the other hand, those who have been treated with radiation due to childhood cancer and people who are being treated with the whole-lung irradiation are at the highest risk of developing breast cancer. The researchers in this study have pointed to this issue and emphasized that the mortality associated with breast cancer in these individuals is significantly higher (standardized incidence ratio [SIR], 43.6; 95\% CI, 27.2-70.3). ${ }^{162}$ However, in addition to chest radiations, people who have been treated after surviving a sarcoma (SIR, 5.3; 95\% CI, 3.6-7.8) or leukemia (SIR ,4.1; 95\% CI, 2.4-6.9) are at higher risk of developing breast cancer at younger age, which can be due to high-dose alkylator and anthracycline chemotherapy. ${ }^{163}$

\section{Conclusion}

Cancer imposes a huge burden on people around the world. ${ }^{164}$ This study investigated the epidemiological aspects and the risk factors associated with breast cancer in the world. The trace of breast cancer as one of the most common form of cancer and causes of mortality among women is seen all over the world, and the mortality rate of breast cancer is higher in less developed countries. The findings of this study showed 
that various factors affect the incidence of breast cancer, of which genetic factors, environmental factors, and lifestyle are the most important ones, and also many factors such as parities, lactation, and exercise play important roles in reducing the risk of this disease.

\section{Disclosure}

The authors report no conflicts of interest in this work.

\section{References}

1. Momenimovahed Z, Salehiniya H. Incidence, mortality and risk factors of cervical cancer in the world. Biomed Res Ther. 2017;4(12):1795-1811.

2. Momenimovahed Z, Ghoncheh M, Pakzad R, Hasanpour H, Salehiniya $\mathrm{H}$. Incidence and mortality of uterine cancer and relationship with Human Development Index in the world. Cukurova Medical Journal. 2017;42(2):233-240.

3. Benson JR, Jatoi I. The global breast cancer burden. Future Oncol. 2012;8(6):697-702.

4. Ferley J, SoerjomataramI I, Ervik M, Dikshit R, Eser S. GLOBOCAN 2012 v1. 0. Cancer Incidence and Mortality Worldwide: IARC Cancer Base No. 11. Lyon, France: International Agency for Research on Cancer; 2013.

5. Zendehdel M, Niakan B, Keshtkar A, Rafiei E, Salamat F. Subtypes of Benign Breast Disease as a Risk Factor for Breast Cancer: A Systematic Review and Meta-Analysis Protocol. Iran J Med Sci. 2018;43(1):1-8.

6. Hortobagyi GN, de la Garza Salazar J, Pritchard K, et al; ABREAST Investigators. The global breast cancer burden: variations in epidemiology and survival. Clin Breast Cancer. 2005;6(5):391-401.

7. Parkin DM, Fernández LM. Use of statistics to assess the global burden of breast cancer. Breast J. 2006;12(s1):S70-S80.

8. Mavaddat N, Pharoah PD, Michailidou K, et al. Prediction of breast cancer risk based on profiling with common genetic variants. JNCI: J Natl Cancer Inst. 2015;107(5):djv036.

9. Khakbazan Z, Taghipour A, Latifnejad Roudsari R, Mohammadi E. Help seeking behavior of women with self-discovered breast cancer symptoms: a meta-ethnographic synthesis of patient delay. PLoS One. 2014;9(12):e110262.

10. Li L, Zhong Y, Zhang $\mathrm{H}$, et al. Association between oral contraceptive use as a risk factor and triple-negative breast cancer: A systematic review and meta-analysis. Mol Clin Oncol. 2017;7(1):76-80.

11. Onitilo AA, Engel JM, Greenlee RT, Mukesh BN. Breast cancer subtypes based on ER/PR and Her2 expression: comparison of clinicopathologic features and survival. Clin Med Res. 2009;7(1-2): 4-13.

12. Milne RL, Kuchenbaecker KB, Michailidou K, et al. Identification of ten variants associated with risk of estrogen-receptor-negative breast cancer. Nat Genet. 2017; 49(12):1767-1778.

13. Ci L, Malone KE, Daling JR. Differences in breast cancer hormone receptor status and histology by race and ethnicity among women 50 years of age and older. Cancer Epidemiol Biomarkers Prev. 2002;11(7):601-607.

14. Yip $\mathrm{CH}$, Bhoo Pathy N, Uiterwaal CS, et al. Factors affecting estrogen receptor status in a multiracial Asian country: An analysis of 3557 cases. Breast. 2011;20(Suppl 2):S60-S64.

15. Bhoo-Pathy N, Hartman M, Yip CH, et al. Ethnic differences in survival after breast cancer in South East Asia. PLoS One. 2012;7(2):e30995.

16. Parise CA, Bauer KR, Brown MM, Caggiano V. Breast cancer subtypes as defined by the estrogen receptor (ER), progesterone receptor (PR), and the human epidermal growth factor receptor 2 (HER2) among women with invasive breast cancer in California, 1999-2004. Breast $J$. 2009;15(6):593-602.
17. Yamashita H, Iwase H, Toyama T, et al. Estrogen receptor-positive breast cancer in Japanese women: trends in incidence, characteristics, and prognosis. Ann Oncol. 2011;22(6):1318-1325.

18. Desantis CE, Ma J, Goding Sauer A, Newman LA, Jemal A. Breast cancer statistics, 2017, racial disparity in mortality by state. CA Cancer J Clin. 2017;67(6):439-448.

19. DeSantis C, Ma J, Bryan L, Jemal A. Breast cancer statistics, 2013. CA Cancer J Clin. 2014;64(1):52-62.

20. Ghoncheh M, Pournamdar Z, Salehiniya H. Incidence and Mortality and Epidemiology of Breast Cancer in the World. Asian Pac J Cancer Prev. 2016;17(S3):43-46.

21. Youlden DR, Cramb SM, Yip CH, Baade PD. Incidence and mortality of female breast cancer in the Asia-Pacific region. Cancer Biol Med. 2014;11(2):101-115.

22. Ghoncheh M, , Momenimovahed Z, Salehiniya H. Epidemiology, Incidence and Mortality of Breast Cancer in Asia. Asian Pac J Cancer Prev. 2016;17(S3):47-52.

23. Gomez SL, Von Behren J, Mckinley M, et al. Breast cancer in Asian Americans in California, 1988-2013: increasing incidence trends and recent data on breast cancer subtypes. Breast Cancer Res Treat. 2017;164(1):139-147.

24. Cancer IAfRo. GLOBOCAN 2012: estimated cancer incidence, mortality and prevalence worldwide in 2012. Lyon, France: International Agency for Research on Cancer; 2012.

25. Rojas K, Stuckey A. Breast Cancer Epidemiology and Risk Factors. Clin Obstet Gynecol. 2016;59(4):651-672.

26. Williams LJ, Fletcher E, Douglas A, et al. Retrospective cohort study of breast cancer incidence, health service use and outcomes in Europe: a study of feasibility. Eur J Public Health. 2018;28(2):327-332.

27. Abdulrahman GO Jr, Rahman GA. Epidemiology of Breast Cancer in Europe and Africa. J Cancer Epidemiol. 2012;2012(12):915610.

28. Clèries R, Rooney RM, Vilardell M, Espinàs JA, Dyba T, Borras JM. Assessing predicted age-specific breast cancer mortality rates in 27 European countries by 2020. Clin Transl Oncol. 2018;20(3):313-321.

29. Ghoncheh M, Mohammadian-Hafshejani A, Salehiniya H. Incidence and Mortality of Breast Cancer and their Relationship to Development in Asia. Asian Pac J Cancer Prev. 2015;16(14):6081-6087.

30. Carioli G, Malvezzi M, Rodriguez T, Bertuccio P, Negri E, La Vecchia C. Trends and predictions to 2020 in breast cancer mortality: Americas and Australasia. Breast. 2018;37:163-169.

31. Kim Y, Yoo K-Y, Goodman MT. Differences in Incidence, Mortality and Survival of Breast Cancer by Regions and Countries in Asia and Contributing Factors. Asian Pac J Cancer Prev. 2015;16(7):2857-2870.

32. Azubuike SO, Muirhead C, Hayes L, McNally R. Rising global burden of breast cancer: the case of sub-Saharan Africa (with emphasis on Nigeria) and implications for regional development: a review. World J Surg Oncol. 2018;16(1):63.

33. Fan L, Goss PE, Strasser-Weippl K. Current Status and Future Projections of Breast Cancer in Asia. Breast Care (Basel). 2015;10(6): 72-378.

34. Giordano SH, Buzdar AU, Hortobagyi GN. Breast Cancer in Men. Ann Intern Med. 2002;137(8):678-687.

35. Abdelwahab Yousef AJ. Male Breast Cancer: Epidemiology and Risk Factors. Semin Oncol. 2017;44(4):267-272.

36. Thakur P, Seam RK, Gupta MK, Gupta M, Sharma M, Fotedar V. Breast cancer risk factor evaluation in a Western Himalayan state: A case-control study and comparison with the Western World. South Asian J Cancer. 2017;6(3):106-109.

37. Mahouri K, Dehghani Zahedani M, Zare S. Breast cancer risk factors in south of Islamic Republic of Iran: a case-control study. East Mediterr Health J. 2007;13(6):1265-1273.

38. Assi HA, Khoury KE, Dbouk H, Khalil LE, Mouhieddine TH, El Saghir NS. Epidemiology and prognosis of breast cancer in young women. J Thorac Dis. 2013;5(Suppl 1):S2-S8.

39. Meo SA, Suraya F, Jamil B, et al. Association of ABO and Rh blood groups with breast cancer. Saudi J Biol Sci. 2017;24(7):1609-1613. 
40. Saxena S, Chawla VK, Gupta KK, Gaur KL. Association of ABO blood group and breast cancer in Jodhpur. Indian J Physiol Pharmacol. 2015; 59(1):63-68.

41. Gates MA, Xu M, Chen WY, Kraft P, Hankinson SE, Wolpin BM. ABO blood group and breast cancer incidence and survival. Int J Cancer. 2012;130(9):2129-2137.

42. Flavarjani AM, Hedayatpour B, Nourian SM, Bashardoost N. Study of the association between blood types and breast cancer among Isfahanian women with breast cancer. Adv Biomed Res. 2014;3(1):43.

43. Bhadoria A, Kapil U, Sareen N, Singh P. Reproductive factors and breast cancer: A case-control study in tertiary care hospital of North India. Indian J Cancer. 2013;50(4):316-321.

44. Laamiri FZ, Bouayad A, Hasswane N, Ahid S, Mrabet M, Amina B. Risk Factors for Breast Cancer of Different Age Groups: Moroccan Data? Open J Obstet Gynecol. 2015;05(02):79-87.

45. Clavel-Chapelon F, Launoy G, Auquier A, et al. Reproductive factors and breast cancer risk: Effect of age at diagnosis. Ann Epidemiol. 1995;5(4):315-320.

46. Wu MH, Chou YC, Yu JC, et al. Hormonal and body-size factors in relation to breast cancer risk: a prospective study of 11,889 women in a low-incidence area. Ann Epidemiol. 2006;16(3):223-229.

47. Tamakoshi K, Yatsuya H, Wakai K, et al; JACC Study Group. Impact of menstrual and reproductive factors on breast cancer risk in Japan: Results of the JACC study. Cancer Sci. 2005;96(1):57-62.

48. Nguyen J, Le QH, Duong BH, et al. A matched case-control study of risk factors for breast cancer risk in Vietnam. Int J Breast Cancer. 2016;2016(8):1-7.

49. Fioretti F, Tavani A, Bosetti C, et al. Risk factors for breast cancer in nulliparous women. Br J Cancer. 1999;79(11-12):1923-1928.

50. Dai Q, Liu B, Du Y. Meta-analysis of the risk factors of breast cancer concerning reproductive factors and oral contraceptive use. Front Med China. 2009;3(4):452-458.

51. Ma H, Henderson KD, Sullivan-Halley J, et al. Pregnancy-related factors and the risk of breast carcinoma in situand invasive breast cancer among postmenopausal women in the California Teachers Study cohort. Breast Cancer Res. 2010;12(3):R35.

52. Ma H, Bernstein L, Pike MC, Ursin G. Reproductive factors and breast cancer risk according to joint estrogen and progesterone receptor status: a meta-analysis of epidemiological studies. Breast Cancer Res. 2006;8(4):R43.

53. Balekouzou A, Yin P, Pamatika CM, et al. Reproductive risk factors associated with breast cancer in women in Bangui: a case-control study. BMC Womens Health. 2017;17(1):14.

54. Palmer JR, Wise LA, Horton NJ, Adams-Campbell LL, Rosenberg L. Dual effect of parity on breast cancer risk in African-American women. J Natl Cancer Inst. 2003;95(6):478-483.

55. Butt S, Borgquist S, Anagnostaki L, Landberg G, Manjer J. Parity and age at first childbirth in relation to the risk of different breast cancer subgroups. Int J Cancer. 2009;125(8):1926-1934.

56. Williams LA, Nichols HB, Hoadley KA, et al. Reproductive risk factor associations with lobular and ductal carcinoma in the Carolina Breast Cancer Study. Cancer Causes Control. 2018;29(1):25-32.

57. Beral V, Bull D, Doll R, Peto R, Reeves G; Collaborative Group on Hormonal Factors in Breast Cancer. Breast cancer and abortion: collaborative reanalysis of data from 53 epidemiological studies, including 83000 women with breast cancer from 16 countries. Lancet. 2004;363(9414):1007-1016.

58. Innes KE, Byers TE. First pregnancy characteristics and subsequent breast cancer risk among young women. Int $J$ Cancer. 2004;112(2):306-311.

59. Melbye M, Wohlfahrt J, Andersen A-MN, Westergaard T, Andersen PK. Preterm delivery and risk of breast cancer. $\mathrm{Br}$ J Cancer. 1999;80(3-4):609-613.

60. Vatten LJ, Romundstad PR, Trichopoulos D, Skjærven R. Pre-eclampsia in pregnancy and subsequent risk for breast cancer. Br J Cancer. 2002;87(9):971-973.
61. Cohn BA, Cirillo PM, Christianson RE, van den Berg BJ, Siiteri PK. Placental characteristics and reduced risk of maternal breast cancer. J Natl Cancer Inst. 2001;93(15):1133-1140.

62. Brasky TM, Li Y, Jaworowicz DJ Jr, et al. Pregnancy-related characteristics and breast cancer risk. Cancer Causes Control. 2013;24(9): $1675-1685$.

63. Beaber EF, Buist DSM, Barlow WE, Malone KE, Reed SD, Li CI. Recent oral contraceptive use by formulation and breast cancer risk among women 20 to 49 years of age. Cancer Res. 2014;74(15):4078-4089.

64. Kotsopoulos J, Lubinski J, Moller P, et al; Hereditary Breast Cancer Clinical Study Group. Timing of oral contraceptive use and the risk of breast cancer in BRCA1 mutation carriers. Breast Cancer Res Treat. 2014;143(3):579-586.

65. Marchbanks PA, McDonald JA, Wilson HG, et al. Oral contraceptives and the risk of breast cancer. $N$ Engl J Med. 2002;346(26):2025-2032.

66. Skegg DC, Noonan EA, Paul C, Spears GF, Meirik O, Thomas DB. Depot medroxyprogesterone acetate and breast cancer: a pooled analysis of the World Health Organization and New Zealand studies. JAMA. 1995;273(10):799-804.

67. Zolfaroli I, Tarín JJ, Cano A. Hormonal contraceptives and breast cancer: Clinical data. Eur J Obstet Gynecol Reprod Biol. 2018;S0301-2115(18)30156-30158.

68. Taheripanah R, Balash F, Anbiaee R, Mahmoodi M, Akbari Sene A. Breast Cancer and Ovulation Induction Treatments. Clin Breast Cancer. 2018;18:395-399.

69. Lerner-Geva L, Keinan-Boker L, Blumstein T, et al. Infertility, ovulation induction treatments and the incidence of breast cancer - a historical prospective cohort of Israeli women. Breast Cancer Res Treat. 2006;100(2):201-212.

70. Brinton LA, Scoccia B, Moghissi KS, et al. Breast cancer risk associated with ovulation-stimulating drugs. Hum Reprod. 2004;19(9):2005-2013.

71. Beral V, Bull D, Doll R, Key T, Peto R, Reeves G. Breast cancer and hormone replacement therapy: collaborative reanalysis of data from 51 epidemiological studies of 52,705 women with breast cancer and 108, 411 women without breast cancer. Lancet. 1997;350(9084):1047-1059.

72. Beral V; Million Women Study Collaborators. Breast cancer and hormone-replacement therapy in the Million Women Study. Lancet. 2003;362(9382):419-427.

73. Ross RK, Paganini-Hill A, Wan PC, Pike MC. Effect of hormone replacement therapy on breast cancer risk: estrogen versus estrogen plus progestin. J Natl Cancer Inst. 2000;92(4):328-332.

74. Fournier A, Berrino F, Clavel-Chapelon F. Unequal risks for breast cancer associated with different hormone replacement therapies: results from the E3N cohort study. Breast Cancer Res Treat. 2007;107(1):103-111.

75. Cobain EF, Milliron KJ, Merajver SD. Updates on breast cancer genetics: Clinical implications of detecting syndromes of inherited increased susceptibility to breast cancer. Semin Oncol. 2016;43(5):528-535.

76. Godet I. Gilkes DM. BRCA1 and BRCA2 mutations and treatment strategies for breast cancer. Integr Cancer Sci Ther. 2017;4(1):1-17.

77. Kuchenbaecker KB, Hopper JL, Barnes DR, et al. Risks of Breast, Ovarian, and Contralateral Breast Cancer for BRCA1 and BRCA2 Mutation Carriers. JAMA. 2017;317(23):2402-2416.

78. Ahmed F, Mahmood N, Shahid S, et al. Mutations in Human Interferon $\alpha 2 b$ Gene and Potential as Risk Factor Associated with Female Breast Cancer. Cancer Biother Radiopharm. 2016;31(6):199-208.

79. Yari K, Rahimi Z, Moradi MT, Rahimi Z. The MMP-2 -735 C Allele is a Risk Factor for Susceptibility to Breast Cancer. Asian Pac J Cancer Prev. 2014;15(15):6199-6203.

80. Bravi F, Decarli A, Russo AG. Risk factors for breast cancer in a cohort of mammographic screening program: a nested case-control study within the FRiCaM study. Cancer Med. 2018;7(5):2145-2152.

81. Ahern TP, Sprague BL, Bissell MC, et al. Family history of breast cancer, breast density, and breast cancer risk in a US breast cancer screening population. Cancer Epidemiol Biomarkers Prev. 2017;26(6): 938-944. 
82. Sweeney C, Blair CK, Anderson KE, Lazovich D, Folsom AR. Risk factors for breast cancer in elderly women. Am J Epidemiol. 2004;160(9):868-875.

83. Metcalfe KA, Finch A, Poll A, et al. Breast cancer risks in women with a family history of breast or ovarian cancer who have tested negative for a BRCA1 or BRCA2 mutation. Br J Cancer. 2009;100(2):421-425.

84. Narod SA, Tung N, Lubinski J, et al; Hereditary Breast Cancer Clinical Study Group. A prior diagnosis of breast cancer is a risk factor for breast cancer in BRCA1 and BRCA2 carriers. Curr Oncol. 2014;21(2):64-68.

85. Melvin JC, Wulaningsih W, Hana Z, et al. Family history of breast cancer and its association with disease severity and mortality. Cancer Med. 2016;5(5):942-949.

86. Freund C, Mirabel L, Annane K, Mathelin C. Breastfeeding and breast cancer. Gynecol Obstet Fertil. 2005;33(10):739-744. French.

87. Nazari SS, Mukherjee P. An overview of mammographic density and its association with breast cancer. Breast Cancer. 2018;25(3):259-267.

88. Jeong SH, An YS, Choi JY, et al. Risk Reduction of Breast Cancer by Childbirth, Breastfeeding, and Their Interaction in Korean Women: Heterogeneous Effects Across Menopausal Status, Hormone Receptor Status, and Pathological Subtypes. J Prev Med Public Health. 2017;50(6):401-410.

89. Kwan ML, Bernard PS, Kroenke CH, et al. Breastfeeding, PAM50 tumor subtype, and breast cancer prognosis and survival. J Natl Cancer Inst. 2015;107(7):djv087.

90. Michels KB, Willett WC, Rosner BA, et al. Prospective assessment of breastfeeding and breast cancer incidence among 89,887 women. Lancet. 1996;347(8999):431-436.

91. Brinton LA, Potischman NA, Swanson CA, et al. Breastfeeding and breast cancer risk. Cancer Causes Control. 1995;6(3):199-208.

92. Vierkant RA, Degnim AC, Radisky DC, et al. Mammographic breast density and risk of breast cancer in women with atypical hyperplasia: an observational cohort study from the Mayo Clinic Benign Breast Disease (BBD) cohort. BMC Cancer. 2017;17(1):84.

93. Byrne C, Ursin G, Martin CF, et al. Mammographic density change with estrogen and progestin therapy and breast cancer risk. $J$ Natl Cancer Inst. 2017;109(9):djx001.

94. Kerlikowske K, Gard CC, Tice JA, et al; Breast Cancer Surveillance Consortium. Risk Factors That Increase Risk of Estrogen Receptor-Positive and -Negative Breast Cancer. J Natl Cancer Inst. 2017;109(5):djw276.

95. Eriksson M, Czene K, Pawitan Y, Leifland K, Darabi H, Hall P. A clinical model for identifying the short-term risk of breast cancer. Breast Cancer Res. 2017;19(1):29.

96. Román M, Quintana MJ, Ferrer J, Sala M, Castells X. Cumulative risk of breast cancer screening outcomes according to the presence of previous benign breast disease and family history of breast cancer: supporting personalised screening. Br J Cancer. 2017;116(11):1480-1485.

97. Socolov D, Anghelache I, Ilea C, Socolov R, Carauleanu A. Benign breast disease and the risk of breast cancer in the next 15 years. Rev Med Chir Soc Med Nat Iasi. 2015;119(1):135-140.

98. Arthur R, Wang Y, Ye K, et al. Association between lifestyle, menstrual/ reproductive history, and histological factors and risk of breast cancer in women biopsied for benign breast disease. Breast Cancer Res Treat. 2017;165(3):623-631.

99. Hartmann LC, Sellers TA, Frost MH, et al. Benign breast disease and the risk of breast cancer. $N$ Engl J Med. 2005;353(3):229-237.

100. Miller ER, Wilson C, Chapman J, et al. Connecting the dots between breast cancer, obesity and alcohol consumption in middle-aged women: ecological and case control studies. BMC Public Health. 2018;18(1):460.

101. Lahmann PH, Hoffmann K, Allen N, et al. Body size and breast cancer risk: Findings from the European prospective investigation into cancer and nutrition (EPIC). Int J Cancer. 2004;111(5):762-771.

102. Chen M-J, Wu WY-Y, Yen AM-F, et al. Body mass index and breast cancer: analysis of a nation-wide population-based prospective cohort study on 1393985 Taiwanese women. Int JObes (Lond). 2016;40(3):524-530.
103. Rosner B, Eliassen AH, Toriola AT, et al. Weight and weight changes in early adulthood and later breast cancer risk. Int J Cancer. 2017;140(9):2003-2014.

104. Kessous R, Davidson E, Meirovitz M, Sergienko R, Sheiner E. Prepregnancy obesity: a risk factor for future development of ovarian and breast cancer. Eur J Cancer Prev. 2017;26(2):151-155.

105. Berclaz G, Li S, Price KN, et al; International Breast Cancer Study Group. Body mass index as a prognostic feature in operable breast cancer: the International Breast Cancer Study Group experience. Ann Oncol. 2004;15(6):875-884.

106. Scholz C, Andergassen U, Hepp P, et al. Obesity as an independent risk factor for decreased survival in node-positive high-risk breast cancer. Breast Cancer Res Treat. 2015;151(3):569-576.

107. Opdahl S, Alsaker MD, Janszky I, Romundstad PR, Vatten LJ. Joint effects of nulliparity and other breast cancer risk factors. Br J Cancer. 2011;105(5):731-736.

108. Vieira R, Tobar JSS, Dardes R, Claudio L, Thuler S. Alcohol Consumption as a Risk Factor for Breast Cancer Development: A Case-Control Study in Brazil. Asian Pac J Cancer Prev. 2018;19(3):703-707.

109. Romieu I, Scoccianti C, Chajès V, et al. Alcohol intake and breast cancer in the European prospective investigation into cancer and nutrition. Int J Cancer. 2015;137(8):1921-1930.

110. Baglia ML, Malone KE, Tang MC, Li CI. Alcohol Intake and Risk of Breast Cancer by Histologic Subtype and Estrogen Receptor Status Among Women Aged 55 to 74 Years. Horm Cancer. 2017;8(4):211-218.

111. Park SY, Kolonel LN, Lim U, White KK, Henderson BE, Wilkens LR. Alcohol consumption and breast cancer risk among women from five ethnic groups with light to moderate intakes: the Multiethnic Cohort Study. Int J Cancer. 2014;134(6):1504-1510.

112. Luo J, Margolis KL, Wactawski-Wende J, et al. Association of active and passive smoking with risk of breast cancer among postmenopausal women: a prospective cohort study. BMJ. 2011;342:d1016.

113. Xue F, Willett WC, Rosner BA, Hankinson SE, Michels KB. Cigarette smoking and the incidence of breast cancer. Arch Intern Med. 2011;171(2):125-133.

114. Tong JH, Li Z, Shi J, et al. Passive smoking exposure from partners as a risk factor for $\mathrm{ER}+/ \mathrm{PR}+$ double positive breast cancer in neversmoking Chinese urban women: a hospital-based matched case control study. PLoS One. 2014;9(5):e97498.

115. Bjerkaas E, Parajuli R, Weiderpass E, et al. Smoking duration before first childbirth: an emerging risk factor for breast cancer? Results from 302,865 Norwegian women. Cancer Causes Control. 2013;24(7):1347-1356.

116. Gierach GL, Freedman ND, Andaya A, et al. Coffee intake and breast cancer risk in the NIH-AARP diet and health study cohort. Int $J$ Cancer. 2012;131(2):452-460.

117. Boggs DA, Palmer JR, Stampfer MJ, Spiegelman D, Adams-Campbell LL, Rosenberg L. Tea and coffee intake in relation to risk of breast cancer in the Black Women's Health Study. Cancer Causes Control. 2010;21(11):1941-1948.

118. Li J, Seibold P, Chang-Claude J, et al. Coffee consumption modifies risk of estrogen-receptor negative breast cancer. Breast Cancer Res. 2011;13(3):R49.

119. Oh JK, Sandin S, Strom P, Lof M, Adami HO, Weiderpass E. Prospective study of breast cancer in relation to coffee, tea and caffeine in Sweden. Int J Cancer. 2015;137(8):1979-89.

120. Ganmaa D, Willett WC, Li TY, et al. Coffee, tea, caffeine and risk of breast cancer: a 22-year follow-up. Int J Cancer. 2008;122(9): 2071-2076.

121. Yaghjyan L, Rich S, Mao L, Mai V, Egan KM. Interactions of coffee consumption and postmenopausal hormone use in relation to breast cancer risk in UK Biobank. Cancer Causes Control. 2018;29(6): 519-525.

122. Jordan I, Hebestreit A, Swai B, Krawinkel MB. Dietary patterns and breast cancer risk among women in northern Tanzania: a case-control study. Eur J Nutr. 2013;52(3):905-915. 
123. Taylor EF, Burley VJ, Greenwood DC, Cade JE. Meat consumption and risk of breast cancer in the UK Women's Cohort Study. Br J Cancer. 2007;96(7):1139-1146.

124. Sieri S, Krogh V, Ferrari P, et al. Dietary fat and breast cancer risk in the European Prospective Investigation into Cancer and Nutrition. Am J Clin Nutr. 2008;88(5):1304-1312.

125. Harris HR, Willett WC, Vaidya RL, Michels KB. An adolescent and early adulthood dietary pattern associated with inflammation and the incidence of breast cancer. Cancer Res. 2017;77(5):1179-1187.

126. Rehman S, Husnain SM. A probable risk factor of female breast cancer: study on benign and malignant breast tissue samples. Biol Trace Elem Res. 2014;157(1):24-29.

127. Mctiernan A, Kooperberg C, White E, et al; Women's Health Initiative Cohort Study. Recreational physical activity and the risk of breas cancer in postmenopausal women: the Women's Health Initiative Cohort Study. JAMA. 2003;290(10):1331-1336.

128. Holmes MD, Chen WY, Feskanich D, Kroenke CH, Colditz GA Physical activity and survival after breast cancer diagnosis. JAMA 2005;293(20):2479-2486.

129. Lee J. A Meta-analysis of the Association Between Physical Activity and Breast Cancer Mortality. Cancer Nurs. Epub 2018 Mar 30.

130. Holick CN, Newcomb PA, Trentham-Dietz A, et al. Physical activity and survival after diagnosis of invasive breast cancer. Cancer Epidemiol Biomarkers Prev. 2008;17(2):379-386.

131. Hatse S, Lambrechts D, Verstuyf A, et al. Vitamin D status at breast cancer diagnosis: correlation with tumor characteristics, disease outcome, and genetic determinants of vitamin D insufficiency. Carcinogenesis. 2012;33(7):1319-1326.

132. Park S, Lee DH, Jeon JY, et al. Serum 25-hydroxyvitamin D deficiency and increased risk of breast cancer among Korean women: a casecontrol study. Breast Cancer Res Treat. 2015;152(1):147-154.

133. O’Brien KM, Sandler DP, Taylor JA, Weinberg CR. Serum vitamin D and risk of breast cancer within five years. Environ Health Perspect. 2017;125(7):077004.

134. Shekarriz-Foumani R, Khodaie F. The correlation of plasma 25-hydroxyvitamin $\mathrm{D}$ deficiency with risk of breast neoplasms: a systematic review. Iran J Cancer Prev. 2016;9(3):e4469.

135. Lu C, Sun H, Huang J, et al. Long-Term Sleep Duration as a Risk Factor for Breast Cancer: Evidence from a Systematic Review and Dose-Response Meta-Analysis. Biomed Res Int. 2017;2017:1-11.

136. Xiao Q, Signorello LB, Brinton LA, Cohen SS, Blot WJ, Matthews CE. Sleep duration and breast cancer risk among black and white women. Sleep Med. 2016;20:25-29.

137. Chiu HY, Huang CJ, Fan YC, Tsai PS. Insomnia But Not Hypnotics Use Associates with the Risk of Breast Cancer: A Population-Based Matched Cohort Study. J Womens Health (Larchmt). Epub 2018 Mar 12.

138. Soucise A, Vaughn C, Thompson CL, et al. Sleep quality, duration, and breast cancer aggressiveness. Breast Cancer Res Treat. 2017;164(1):169-178.

139. Marinac CR, Nelson SH, Flatt SW, Natarajan L, Pierce JP, Patterson RE. Sleep duration and breast cancer prognosis: perspectives from the Women's Healthy Eating and Living Study. Breast Cancer Res Treat. 2017;162(3):581-589.

140. Vogtmann E, Levitan EB, Hale L, et al. Association between sleep and breast cancer incidence among postmenopausal women in the Women's Health Initiative. Sleep. 2013;36(10):1437-1444.

141. Andersen ZJ, Stafoggia M, Weinmayr G, et al. Long-term exposure to ambient air pollution and incidence of postmenopausal breast cancer in 15 European cohorts within the ESCAPE project. Environ Health Perspect. 2017;125(10):107005.

142. Wei Y, Davis J, Bina WF. Ambient air pollution is associated with the increased incidence of breast cancer in US. Int J Environ Health Res. 2012;22(1):12-21.

143. Andersen ZJ, Stafoggia M, Weinmayr G, et al. Long-Term Exposure to Ambient Air Pollution and Incidence of Postmenopausal Breast Cancer in 15 European Cohorts within the ESCAPE Project. Environ Health Perspect. 2017;125(10):107005.
144. Benabu JC, Stoll F, Gonzalez M, Mathelin C. Night work, shift work: Breast cancer risk factor? Gynecol Obstet Fertil. 2015;43(12):791-799. French.

145. Kerenyi NA, Pandula E, Feuer GM. Oncostatic effects of the pineal gland. Drug Metabol Drug Interact. 1990;8(3-4):313-319.

146. Stevens RG, Davis S. The melatonin hypothesis: electric power and breast cancer. Environ Health Perspect. 1996;104(Suppl 1):135-140.

147. Megdal SP, Kroenke CH, Laden F, Pukkala E, Schernhammer ES. Night work and breast cancer risk: a systematic review and meta-analysis. Eur J Cancer. 2005;41(13):2023-2032.

148. Orsini M, Trétarre B, Daurès JP, Bessaoud F. Individual socioeconomic status and breast cancer diagnostic stages: a French case-control study. Eur J Public Health. 2016;26(3):445-450.

149. Lundqvist A, Andersson E, Ahlberg I, Nilbert M, Gerdtham U. Socioeconomic inequalities in breast cancer incidence and mortality in Europe-a systematic review and meta-analysis. Eur J Public Health. 2016;26(5):804-813.

150. Akinyemiju TF, Pisu M, Waterbor JW, Altekruse SF. Socioeconomic status and incidence of breast cancer by hormone receptor subtype. Springerplus. 2015;4(1):508.

151. Gordon NH. Socioeconomic factors and breast cancer in black and white Americans. Cancer Metastasis Rev. 2003;22(1):55-65.

152. Kuzhan A, Adl1 M. The Effect of Socio-Economic-Cultural Factors on Breast Cancer. J Breast Health. 2015;11(1):17-21.

153. Booth CM, Li G, Zhang-Salomons J, Mackillop WJ. The impact of socioeconomic status on stage of cancer at diagnosis and survival: a population-based study in Ontario, Canada. Cancer. 2010;116(17):4160-4167.

154. Wolf I, Sadetzki S, Catane R, Karasik A, Kaufman B. Diabetes mellitus and breast cancer. Lancet Oncol. 2005;6(2):103-111.

155. Tabassum I, Mahmood H, Faheem M. Type 2 Diabetes Mellitus as a Risk Factor for Female Breast Cancer in the Population of Northern Pakistan. Asian Pac J Cancer Prev. 2016;17(7):3255-3258.

156. Larsson SC, Mantzoros CS, Wolk A. Diabetes mellitus and risk of breast cancer: a meta-analysis. Int J Cancer. 2007;121(4):856-862.

157. Muti P, Quattrin T, Grant BJ, et al. Fasting glucose is a risk factor for breast cancer: a prospective study. Cancer Epidemiol Biomarkers Prev. 2002;11(11):1361-1368

158. Tang GH, Satkunam M, Pond GR, et al. Association of metformin with breast cancer incidence and mortality in patients with type 2 diabetes: a GRADE assessed systematic review and meta-analysis. Cancer Epidemiol Biomarkers Prev. 2018;27(6):627-635.

159. Rinaldi S, Peeters PH, Berrino F, et al. IGF-I, IGFBP-3 and breast cancer risk in women: The European Prospective Investigation into Cancer and Nutrition (EPIC). Endocr Relat Cancer. 2006;13(2):593-605.

160. Chang YL, Sheu WH, Lin SY, Liou WS. Good glycaemic control is associated with a better prognosis in breast cancer patients with type 2 diabetes mellitus. Clin Exp Med. 2018;18(3):383-390.

161. John EM, Phipps AI, Knight JA, et al. Medical radiation exposure and breast cancer risk: findings from the Breast Cancer Family Registry. Int J Cancer. 2007;121(2):386-394.

162. Moskowitz CS, Chou JF, Wolden SL, et al. Breast cancer after chest radiation therapy for childhood cancer. J Clin Oncol. 2014;32(21):2217-2223.

163. Henderson TO, Moskowitz CS, Chou JF, et al. Breast cancer risk in childhood cancer survivors without a history of chest radiotherapy: a report from the Childhood Cancer Survivor Study. J Clin Oncol. 2016;34(9):910-918.

164. Momenimovahed Z, Ghoncheh M, Pakzad R, Hasanpour H, Salehiniya $H$. Incidence and mortality of uterine cancer and relationship with Human Development Index in the world. Cukurova Medical Journal. 2017;42(2):233-240.

165. Ferlay J, et al. IARC CancerBase No. 11 [Internet] Lyon, France: International Agency for Research on Cancer; 2013. GLOBOCAN 2012 v1.0, Cancer Incidence and Mortality Worldwide. Available from: http://globocan.iarc.fr. Accessed November 20, 2018.

166. Torre LA, Bray F, Siegel RL, Ferlay J, Lortet-Tieulent J, Jemal A. Global cancer statistics, 2012. CA Cancer J Clin. 2015;65(2):87-108. 


\section{Publish your work in this journal}

Breast Cancer - Targets and Therapy is an international, peerreviewed open access journal focusing on breast cancer research, identification of therapeutic targets and the optimal use of preventative and integrated treatment interventions to achieve improved outcomes, enhanced survival and quality of life for the cancer patient.
The manuscript management system is completely online and includes a very quick and fair peer-review system, which is all easy to use. Visit http://www.dovepress.com/testimonials.php to read real quotes from published authors.

Submit your manuscript here: https://www.dovepress.com/breast-cancer---targets-and-therapy-journal 